\title{
Prevalence and associated factors of myopia among rural school students in Chia-Yi, Taiwan
}

\author{
Li-Ju Lai ${ }^{1}$, Wei-Hsiu Hsu ${ }^{2,3^{*}}$ (D) and Tao-Hsin Tung ${ }^{4}$
}

\begin{abstract}
Background: The prevalence of myopia has increased rapidly worldwide over the past few decades. The aim of this study was to evaluate the prevalence and associated risk factors for myopia in elementary and junior high school students in Chia-Yi, Taiwan.

Methods: We included 5417 students in total from Grade 1-6 $(n=4763)$ and Grade 7-9 $(n=654)$ from Chia Yi County in this population-based study. The students underwent noncycloplegic autorefractometry and an interview with a structured questionnaire.

Results: For this study population, the prevalence of myopia and high myopia was 42.0 and $2.0 \%$, respectively, revealing a statistically significant increase with increasing age $(p<0.05)$. Junior high school students (aged 13-15) showed a greater prevalence of myopia than elementary school students (aged 7-12) (55.8\% vs. 40.1\%, respectively, $p<0.001$ ). Multiple logistic regression analysis showed that associated factors of myopia were body height (odds ratio [OR]: 1.05, 95\% confidence interval [Cl]: 1.05-1.06), body mass index (OR: 0.98, 95\% Cl: 0.96-1.00), and ocular alignment (horizontal heterophoria vs. orthophoria, OR: 2.37, 95\% Cl: 2.08-2.70; tropia vs. orthophoria, OR: 1.94, 95\% Cl: 1.50-2.52) for elementary school students, whereas in junior high school students, they included body height (OR: 1.02, 95\% Cl: 1.01-1.04) and ocular alignment (heterophoria vs. orthophoria, OR: 2.20, 95\% Cl: 1.56-3.10).

Conclusions: This study provided epidemiological data on myopia in rural school students in Chia-Yi, Taiwan, and demonstrated the association between heterophoria and myopia. Correction of refractive errors in the students remained a challenge.
\end{abstract}

Keywords: Myopia, School students, Rural, Taiwan, Heterophoria

\section{Background}

The prevalence of myopia has increased rapidly worldwide over the past few decades, particularly in East Asia [1-4]. Moreover, $10-20 \%$ of such patients progress to high myopia, with an increased risk of complications such as retinal detachment, glaucoma, cataract, and pathological myopia $[5,6]$. The prevalence of myopia

\footnotetext{
* Correspondence: 7572@cgmh.org.tw

${ }^{2}$ School of Medicine, Chang Gung University, Lin-ko, Taoyuan City, Taiwan ${ }^{3}$ Department of Orthopedics Surgery, Chang Gung Memorial Hospital, No. 6, West section, Chia-Pu Road, Pu-Zih City, Chia-Yi County, Taiwan 61363 Full list of author information is available at the end of the article
}

and high myopia has been estimated to increase significantly from 2000 to 2050 [7]. Recently, epidemiological studies performed to investigate the prevalence and risk factors for myopia have provided information on modifiable risk factors for myopia, including duration of outdoor activities, duration of near work, and vision screening [8-12]. Meanwhile, routine screening can detect this disorder early to prompt appropriate clinical intervention.

In Taiwan, the prevalence rates of myopia in elementary school children aged 7 years were $5.8,3.0,6.6,12.0$, 20.0, 19.6, and 17.9\% in 1983, 1986 1990, 1995, 2000, 
2006, and 2010, respectively. The rates for the same years among children aged 12 years were correspondingly $36.7,27.5,35.2,55.5,61.0,62$, and $66 \%$. At the junior high school level, the rates for the corresponding years were 64.2, 61.6, 74.0, 76.0, and 81.0\% [1]. The Ministry of Education in Taiwan launched a myopia prevention programme for young children in 2009. This intervention covers preventive measures, such as outdoor activities for $2 \mathrm{~h}$ every day, classroom clearance between classes for outdoor activities, 10 min of disruption in near vision every $30 \mathrm{~min}$, vision screening by a school nurse twice a year, and cycloplegic refractometry to screen high- risk groups for myopia. However, exposure to smartphone and smart devices among children can lead to long hours of near work. Thus, myopia prevention is a challenge [8].

We therefore performed this population-based study to understand the prevalence of myopia and risk factors for myopia, including horizontal heterophoria, intraocular pressure, and sleep duration, among school children in the rural setting of Chia-Yi, a prefecture, in south Taiwan.

\section{Methods}

\section{Participants}

We recruited students of 33 elementary schools and 3 junior high schools from July 2014 to June 2015 in ChiaYi, Taiwan, for this cross-sectional study. In total, 5417 participants underwent surveys of refraction and eye health as well as associated life style investigations. We included two cohorts, namely the age groups of 7-12 years and 13-15 years, that comprised students from elementary and junior high schools, respectively. We contacted the local administration of the Education and School Board to request their cooperation. The Institutional Review Board of Chang Gung Foundation (1024827B) approved our study, and we followed the tenets of the Declaration of Helsinki. Written consent was obtained from the parents or guardians of all children before the study.

\section{Eye examination}

We used an examination environment setting of a classroom with blackout curtains for all the participants. The same investigating team administered all survey questionnaires and examinations to reduce individual errors. The body weight and height were measured. Gender, sleep duration and eye related symptoms was obtained through questionnaire. Noncycloplegic refractive errors were assessed using an auto-refractor (Autorefractometer, ARK-1, Nidek Co.,LTD., Aichi, Japan) [9]. Children presenting with a history of ocular and physical pathology, strabismus, and amblyopia were excluded. We obtained this medical data through questionnaire from children's parents. (Supplementary doc. 1) The definition of refractive errors was based on spherical equivalent (SE) refraction calculated as the spherical dioptre plus one half of the cylindrical dioptre. An SE of $\leq$ $-1.0 \mathrm{D}$ in one or both eyes was defined as myopia and categorised into low myopia (from $-1.0 \mathrm{D}$ to $-6.0 \mathrm{D}$ ) and high myopia ( $\leq-6.0 \mathrm{D})$. We evaluated ocular alignment using corneal reflections observations (Hirschberg test), followed by the monocular cover-uncover test. Briefly, one eye of the participant was covered, and the examiner looked for any movement in the opposite uncovered eye. Tropia was indicated by such movement. While heterophoria was indicated in case of movement of the covered eye when the cover was applied and movement in the opposite direction (a fusional movement) as the cover was removed. If the patient had heterophoria, the eye would be straight before and after the cover-uncover test. The deviation appeared during the test because of the interruption of binocular vision. We included both exophoria and esophoria in the horizontal heterophoria group for further analysis. We analysed the risk factors and prevalence of myopia and high myopia for both children with and without myopia and presented the adjusted odds ratio values for all risk factors.

\section{Statistical analysis}

Statistical analysis was conducted using Statistical Package for the Social Sciences for Windows (v 20.0; SPSS Inc., Chicago, IL, USA); data are presented as numbers (\%) and mean \pm SD for fractions and continuous variables, respectively, as appropriate, and myopia data are presented as prevalence (95\% confidence interval $[\mathrm{CI}]$ ). The Pearson correlation test measured the relation between age and prevalence as well as SE refractive error. Univariate logistic analysis regression was adopted to assess differences in categorical variables. Multinomial logistic regression is the extension of the (binary) logistic regression in which the categorical dependent outcome has more than two levels. This method was also performed to provide a set of coefficients for each of the two comparisons of myopia and to investigate the independence of factors associated with the prevalence of myopia. Significance was set at $p<0.05$.

\section{Results}

We recruited 5417 participants in total aged $7-15$ years in the present study; 4763 and 654 participants were included in the elementary and junior high school groups, respectively (Table 1). Myopia was prevalent in 40.1 and $55.8 \%$ of elementary and junior high school groups, respectively $(p<0.001)$ Regarding ocular alignment, 40.4 and $42.0 \%$ of the elementary and junior high school groups showed horizontal heterophoria, respectively $(p=0.68)$. The junior high school group showed more 
Table 1 Comparison of baseline characteristics between students of elementary and junior high schools $(n=5417)$

\begin{tabular}{|c|c|c|c|}
\hline & $\begin{array}{l}\text { Elementary school (aged 7-12) }(n=4763) \\
\text { mean } \pm \text { SD or } n(\%)\end{array}$ & $\begin{array}{l}\text { Junior high school (aged 13-15) }(n=654) \\
\text { mean } \pm \text { SD or } \mathrm{n}(\%)\end{array}$ & $P$-value \\
\hline Male & $2491(52.3)$ & $368(56.3)$ & 0.03 \\
\hline Body Height (cm) & $136 \pm 12$ & $157 \pm 11$ & $<0.001$ \\
\hline BMI $\left(\mathrm{kg} / \mathrm{m}^{2}\right)$ & $18.8 \pm 4.1$ & $21.3 \pm 4.7$ & $<0.001$ \\
\hline Spherical Equivalent (SE), OD (diopter) & $-1.06 \pm 1.72$ & $-1.86 \pm 1.99$ & $<0.001$ \\
\hline Intraocular pressure (IOP),OD (mmHg) & $17.2 \pm 4.3$ & $17.27 \pm 4.4$ & 0.66 \\
\hline Sleep duration, $\geqq 8 \mathrm{~h} /$ day & $4045(84.9)$ & $418(63.9)$ & $<0.001$ \\
\hline Ocular alignment & & & 0.68 \\
\hline Orthophoria & $2518(52.9)$ & $338(51.7)$ & \\
\hline Horizontal heterophoria & $1923(40.4)$ & $275(42.0)$ & \\
\hline Tropia & $332(6.8)$ & $41(6.3)$ & \\
\hline Myopia & & & $<0.001$ \\
\hline Hyperopia & $51(1.1)$ & $0(0.0)$ & \\
\hline No Myopia & $2721(57.1)$ & $262(40.1)$ & \\
\hline Myopia & $1910(40.1)$ & $365(55.8)$ & \\
\hline High Myopia & $81(1.7)$ & $27(4.1)$ & \\
\hline
\end{tabular}

SE and higher incidence of myopia than the elementary school group $(p<0.001)$ (Table 1). The distribution of ocular alignment was interestingly similar in both groups.

The prevalence rates of myopia and high myopia increased with age $(\mathrm{p}<0.001)$ (Fig. 1a and $\mathrm{b})$, along with the $\mathrm{SE}$ refractive error $(p<0.001)$ (Fig. 2). Univariate analyses indicated body height, body mass index, intraocular pressure, and ocular alignment as myopia-associated factors in the elementary school group (Table 2). Similar factors were also found for high myopia, and gender was an additional factor. In the junior high school group, body height, body mass index, and ocular alignment significantly affected the development of myopia, whereas only body mass index and ocular alignment were the associated factors of high myopia.

The effect of independent associated risk factors on myopia and high myopia was investigated through multinomial logistic regression. Body height (OR: 1.05, 95\% CI: 1.05-1.06), body mass index (OR: 0.98, 95\% CI: 0.96-1.00), and ocular alignment (horizontal heterophoria vs. orthophoria, OR: 2.37, 95\% CI: 2.08-2.70; tropia vs. orthophoria, OR: $1.94,95 \%$ CI: 1.50-2.52) were significant factors for myopia in the elementary school group after adjustment for confounding factors. (Table 3) Only body height (OR: 1.10, 95\% CI: 1.07-1.23) and ocular alignment (horizontal heterophoria vs. orthophoria, OR: 9.79, 95\% CI: 5.06-19.0; tropia vs. orthophoria, OR: 16.8, 95\% CI: 7.57-37.3) were
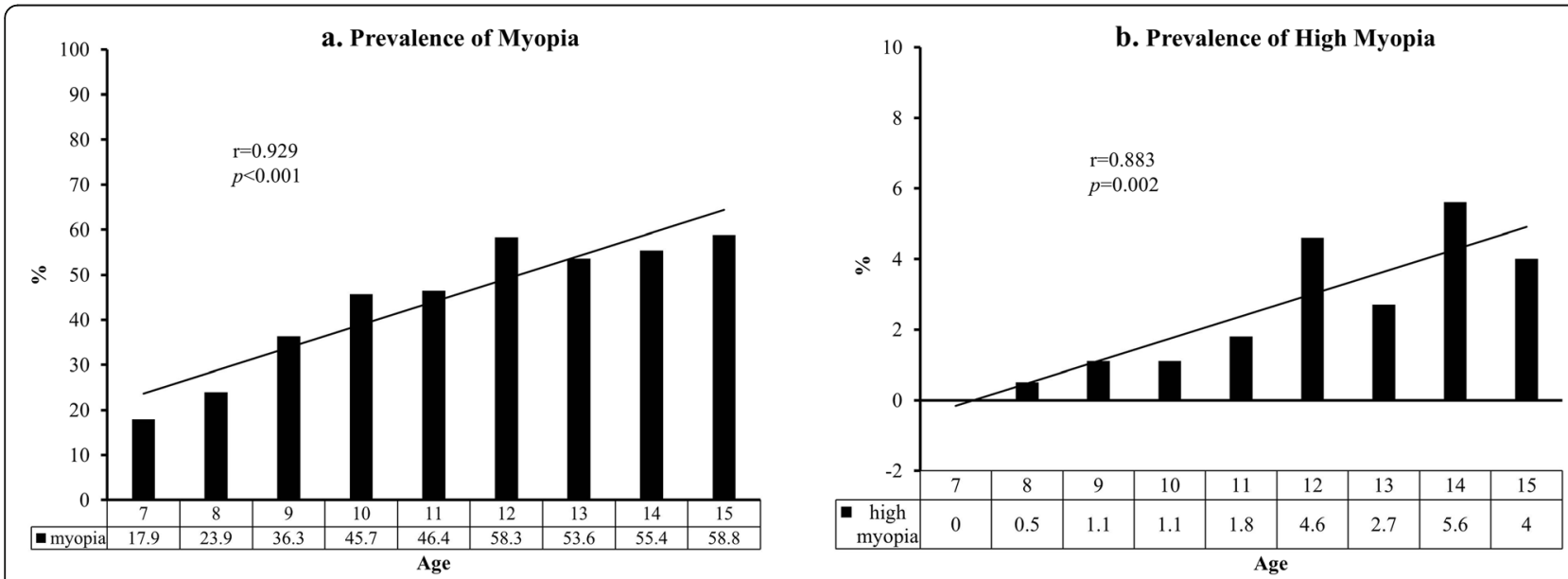

Fig. 1 a. Prevalence of Myopia. b. Prevalence of High Myopia 


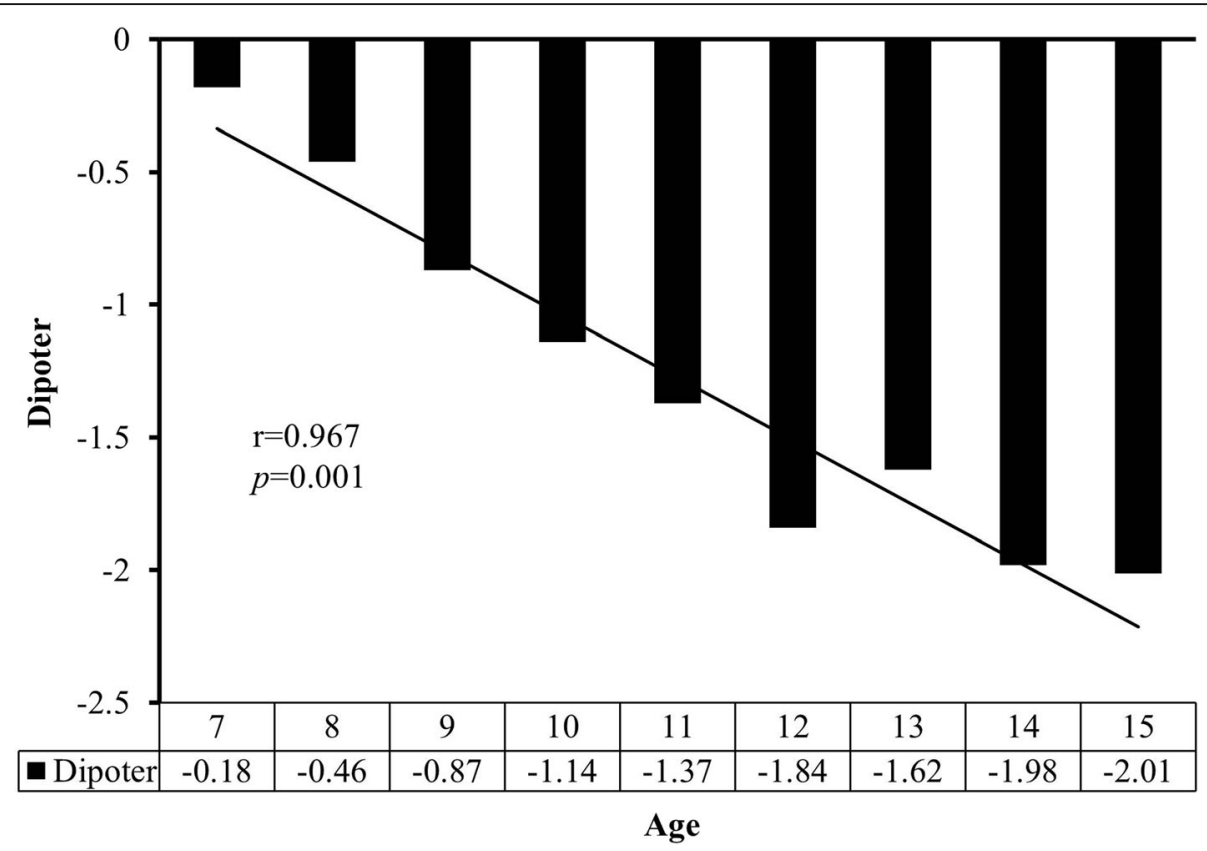

Fig. 2 Mean of spherical equivalent refractive error stratified by age

Table 2 Univariate analysis for comparison of characteristics in myopia and high myopia groups $(n=5417)$

Myopia $(n=1910)$ vs. No Myopia $(n=2721) \quad$ High Myopia $(n=81)$ vs. No Myopia $(n=2721)$
OR
$95 \% \mathrm{Cl}$
OR
$95 \% \mathrm{Cl}$

Elementary school (aged 7-12) $(n=4763)$

$\begin{array}{ll}\text { Gender (Female vs. Male) } & 1.05 \\ \text { Body Height (cm) } & 1.05 \\ \text { BMI }\left(\mathrm{kg} / \mathrm{m}^{2}\right) & 1.05 \\ \text { Intraocular pressure (IOP),OD (mmHg) } & 1.03 \\ \text { Sleep( } \geqq 8 \mathrm{~h} / \text { day vs. < } 8 \mathrm{~h} / \text { day) } & 1.01 \\ \text { Headache (yes vs. no) } & 1.16 \\ \text { Horizontal heterophoria vs. Orthophoria } & 2.28 \\ \text { Tropia vs. Orthophoria } & 1.8\end{array}$

1.05

1.05

1.05

1.03

1.01

1.16

2.28

1.84

Myopia ( $n=365)$ vs. No Myopia $(n=262)$

$\mathrm{OR}$

Junior high school (aged 13-15) $(n=654)$

$\begin{array}{ll}\text { Gender (Female vs. Male) } & 0.91 \\ \text { Body Height (cm) } & 1.02 \\ \text { BMI }\left(\mathrm{kg} / \mathrm{m}^{2}\right) & 1.05 \\ \text { Intraocular pressure (IOP),OD (mmHg) } & 1.01 \\ \text { Sleep } \geqq 8 \text { h. vs. < 8 h.) } & 1.23 \\ \text { Headache (yes vs. no) } & 1.65 \\ \text { Horizontal heterophoria vs. Orthophoria } & 2.24 \\ \text { Tropia vs. Orthophoria } & 1.72\end{array}$

$\begin{array}{lll}0.93-1.18 & 1.83 & 1.16-2.88 \\ 1.04-1.05 & 1.09 & 1.07-1.12 \\ 1.04-1.07 & 1.10 & 1.05-1.16 \\ 1.01-1.04 & 1.05 & 1.00-1.11 \\ 0.86-1.19 & 0.58 & 0.34-0.97 \\ 0.93-1.45 & 0.52 & 0.16-1.68 \\ 2.02-2.58 & 9.36 & 4.87-17.9 \\ 1.44-2.35 & 15.7 & 7.20-34.6\end{array}$

High Myopia $(n=27)$ vs. No Myopia $(n=262)$

$\mathrm{OR}$

$95 \% \mathrm{Cl}$
0.71

1.03

1.10

0.98

1.85

1.22

6.64

15.5
$0.31-1.60$

$0.99-1.08$

$1.02-1.19$

$0.89-1.07$

$0.76-4.53$

2.35-18.8

2.35-18.75

4.17-57.7 
Table 3 Multinomial logistic regression of associated factors of myopia and high myopia in elementary and junior high school students $(n=5417)$

\begin{tabular}{|c|c|c|c|c|}
\hline & \multicolumn{2}{|c|}{ Myopia $(n=1718)$ vs. No Myopia $(n=2972)$} & \multicolumn{2}{|c|}{ High Myopia $(n=73)$ vs. No Myopia $(n=2972)$} \\
\hline & OR & $95 \% \mathrm{Cl}$ & OR & $95 \% \mathrm{Cl}$ \\
\hline \multicolumn{5}{|l|}{ Elementary school (aged 7-12) $(n=4763)$} \\
\hline Body Height $(\mathrm{cm})$ & 1.05 & $1.05-1.06$ & 1.10 & $1.07-1.12$ \\
\hline BMI $\left(\mathrm{Kg} / \mathrm{m}^{2}\right)$ & 0.98 & $0.96-1.00$ & 0.98 & $0.93-1.04$ \\
\hline Intraocular pressure (IOP),OD (mmHg) & 1.02 & $1.00-1.03$ & 1.04 & $0.99-1.09$ \\
\hline Horizontal heterophoria vs. Orthophoria & 2.37 & $2.08-2.70$ & 9.79 & $5.06-19.0$ \\
\hline \multirow[t]{3}{*}{ Tropia vs. Orthophoria } & 1.94 & $1.50-2.52$ & 16.8 & 7.57-37.3 \\
\hline & \multicolumn{2}{|c|}{ Myopia $(n=340)$ vs. No Myopia $(n=289)$} & \multicolumn{2}{|c|}{ High Myopia $(n=25)$ vs. No Myopia $(n=289)$} \\
\hline & OR & $95 \% \mathrm{Cl}$ & $\mathrm{OR}$ & $95 \% \mathrm{Cl}$ \\
\hline \multicolumn{5}{|l|}{ Junior high school (aged 13-15) $(n=654)$} \\
\hline Body Height (cm) & 1.02 & $1.00-1.03$ & 1.03 & $0.98-1.08$ \\
\hline $\mathrm{BMI}\left(\mathrm{Kg} / \mathrm{m}^{2}\right)$ & 1.03 & $0.99-1.07$ & 1.07 & $0.98-1.16$ \\
\hline Horizontal heterophoria vs. Orthophoria & 2.20 & $1.56-3.10$ & 6.36 & $2.24-18.1$ \\
\hline Tropia vs. Orthophoria & 1.73 & $0.84-3.57$ & 15.3 & $4.06-57.7$ \\
\hline
\end{tabular}

significant factors for high myopia in the elementary school group. In the junior high school group, body height and ocular alignment were significant factors for myopia, and only ocular alignment (horizontal heterophoria vs. orthophoria, OR: 6.36, 95\% CI: 2.24-18.1; tropia vs. orthophoria, OR: 15.3, 95\% CI: 4.06-57.7) was significant for high myopia.

\section{Discussion}

\section{Prevalence and associated factors of myopia}

Despite the implementation of the myopia prevention programme, the prevalence of myopia remained high in the rural prefecture of Taiwan. Horizontal heterophoria was an associated factor for myopia in children in both elementary and junior high school groups, with ORs of 2.37 and 2.20, respectively. It was also associated with high myopia, with ORs of 9.79 and 6.36 for children in elementary and junior high school groups, respectively. Rose et al. and Dirani et al. suggested that outdoor activity is an independent factor negatively associated with myopia $[10,11]$. Thus, a strategy based on these findings can be developed to prevent myopia and high myopia [12]. Although the Ministry of Education in Taiwan launched a project using these very strategies in 2009, our study demonstrated that the prevalence of myopia remained high. This may be possible because of children being increasingly exposed to computers, communication and electronic consumer products, and after-school tutoring classes in Taiwan. Meanwhile, controversy exists whether near work is associated with myopia [13-15].

Our results demonstrated an increase in the prevalence of myopia with increasing age, which is compatible with the results in the literature [16]. The literature also shows that the annual incidence of myopia increased with age from $19.1 \%$ at aged 7 years to $30.2 \%$ at aged 11 years [16]. The increase in the prevalence with age would not be solely accumulation of myopic children, but also the increasing new myopia with age [16]. Therefore, more effort is needed in preventing new myopia as well as delaying the onset of myopia.

The association between myopia prevalence and horizontal heterophoria was further investigated in our study. Heterophoria was previously suggested to be associated with myopia in pre-school and elementary school children [17-20]. We demonstrated a close link between horizontal heterophoria and myopia. Children with heterophoria may progress to myopia though convergence accommodation [21-24]. Reduction of concomitant accommodation has been found to delay the progression of moderate myopia [25]. However, because we were unable to determine whether heterophoria is a risk factor for myopia or vice versa, further study is needed to clarify the link between myopia and heterophoria [18].

\section{Methodological considerations}

This study has several limitations. First, we used noncycloplegic refraction because this was a population-based screening study, and cycloplegia was not well accepted by children and their parents. Choong et al. reported that autorefractors had a tendency towards minus overcorrection under noncycloplegic conditions [26]. Therefore, we used - 1.0 D to define myopia. The noncycloplegic autorefraction test was more convenient for vision-screening than the best-corrected visual acuity test and cycloplegic refraction test [9]. Second, we only evaluated a rural region in Taiwan. The prevalence of myopia is usually higher in 
urban areas than in rural areas. However, our results showed a high prevalence of myopia in the rural region, which warrants further evaluation. The study still retained sufficient statistical power to evaluate the presence of various risk factors for myopia given the rather large sample size. Finally, because our measurements were performed at a single point in time, they may not reflect long-term exposure to important demographic or biochemical factors.

\section{Conclusion}

The prevalence of myopia was high at 40.1 and $55.8 \%$ among elementary school and junior high school groups, respectively, in the rural area of Chia-Yi. Heterophoria was associated with myopia and high myopia.

\section{Supplementary information}

Supplementary information accompanies this paper at https://doi.org/10. 1186/s12886-020-01590-y.

Additional file 1. Questionnaire. This document represented the questionnaire utilized in the present study.

\section{Abbreviations}

SE: Spherical equivalent; OR: Odds ratio

\section{Acknowledgments}

Not applicable.

\section{Authors' contributions}

$L J$ participated in the design of the study, collected data, performed the statistical analysis, and drafted the manuscript. WHH participated in the design of the study and revision of the manuscript. WHH and THT participated in the study and statistical analysis. All authors read and approved the final manuscript.

\section{Funding}

This work was supported in part by grants from Chang Gung Memorial Hospital in Taiwan (Grant No. CMRPG6D0363). The grant covered the personnel expenses and experimental consumables. The funding body/ bodies played no roles in the design of the study and collection, analysis, and interpretation of data and in writing the manuscript.

\section{Availability of data and materials}

The datasets analysed during the current study are not publicly available for confidentiality reasons; however, the corresponding author will provide them on reasonable request.

\section{Ethics approval and consent to participate}

This study protocol was approved by the Institutional Review Board of Chang Gung Medical Foundation (Number: 102-4827B). All patients provided written informed consent.

\section{Consent for publication}

Not applicable.

\section{Competing interests}

The authors declared no competing interests.

\section{Author details}

'Ophthalmology, Universal Eye centre, Chia-Yi, Taiwan. ${ }^{2}$ School of Medicine, Chang Gung University, Lin-ko, Taoyuan City, Taiwan. ${ }^{3}$ Department of Orthopedics Surgery, Chang Gung Memorial Hospital, No. 6, West section, Chia-Pu Road, Pu-Zih City, Chia-Yi County, Taiwan 61363. ${ }^{4}$ Department of Medical Research and Education, Cheng-Hsin General Hospital, Taipei, Taiwan.
Received: 10 July 2019 Accepted: 29 July 2020

Published online: 05 August 2020

\section{References}

1. Lin LL, Shih YF, Hsiao CK, Chen CJ. Prevalence of myopia in Taiwanese schoolchildren: 1983 to 2000. Ann Acad Med Singap. 2004;33(1):27-33.

2. Matsumura $H_{1}$ Hirai $H$. Prevalence of myopia and refractive changes in students from 3 to 17 years of age. Surv Ophthalmol. 1999;44(Suppl 1): S109-15.

3. Yoon KC, Mun GH, Kim SD, Kim SH, Kim CY, Park KH, Park YJ, Baek SH, Song $\mathrm{SJ}$, Shin JP, et al. Prevalence of eye diseases in South Korea: data from the Korea National Health and nutrition examination survey 2008-2009. Korean J Ophthalmol. 2011;25(6):421-33.

4. You QS, Wu LJ, Duan JL, Luo YX, Liu LJ, Li X, Gao Q, Wang W, Xu L, Jonas $J B$, et al. Prevalence of myopia in school children in greater Beijing: the Beijing childhood eye Study. Acta Ophthalmol. 2014;92(5):e398-406.

5. Iwase A, Araie M, Tomidokoro A, Yamamoto T, Shimizu H, Kitazawa Y, Tajimi Study G. Prevalence and causes of low vision and blindness in a Japanese adult population: the Tajimi Study. Ophthalmology. 2006;113(8):1354-62.

6. Saw SM, Gazzard G, Shih-Yen EC, Chua WH. Myopia and associated pathological complications. Ophthalmic Physiol Opt. 2005;25(5):381-91.

7. Holden BA, Fricke TR, Wilson DA, Jong M, Naidoo KS, Sankaridurg P, Wong TY, Naduvilath TJ, Resnikoff S. Global prevalence of myopia and high myopia and temporal trends from 2000 through 2050. Ophthalmology. 2016;123(5):1036-42

8. Ip JM, Saw SM, Rose KA, Morgan IG, Kifley A, Wang JJ, Mitchell P. Role of near work in myopia: findings in a sample of Australian school children. Invest Ophthalmol Vis Sci. 2008;49(7):2903-10.

9. Wu LJ, You QS, Duan JL, Luo YX, Liu LJ, Li X, Gao Q, Zhu HP, He Y, Xu L, et al. Prevalence and associated factors of myopia in high-school students in Beijing. PLoS One. 2015;10(3):e0120764.

10. Rose KA, Morgan IG, Ip J, Kifley A, Huynh S, Smith W, Mitchell P. Outdoor activity reduces the prevalence of myopia in children. Ophthalmology. 2008; 115(8):1279-85.

11. Dirani M, Tong L, Gazzard G, Zhang X, Chia A, Young TL, Rose KA, Mitchell $P$, Saw SM. Outdoor activity and myopia in Singapore teenage children. Br J Ophthalmol. 2009;93(8):997-1000.

12. Wong TY, Hyman L. Population-based studies in ophthalmology. Am J Ophthalmol. 2008;146(5):656-63.

13. Huang HM, Chang DS, Wu PC. The association between near work activities and myopia in children-a systematic review and meta-analysis. PLoS One. 2015;10(10):e0140419.

14. Li SM, Li SY, Kang MT, Zhou Y, Liu LR, Li H, Wang YP, Zhan SY, Gopinath B, Mitchell $P$, et al. Near work related parameters and myopia in Chinese children: the Anyang childhood eye Study. PLoS One. 2015;10(8):e0134514.

15. Lin Z, Gao TY, Vasudevan B, Ciuffreda KJ, Liang YB, Jhanji V, Fan SJ, Han W, Wang NL. Near work, outdoor activity, and myopia in children in rural China: the Handan offspring myopia study. BMC Ophthalmol. 2017;17(1):203.

16. Wang SK, Guo Y, Liao C, Chen Y, Su G, Zhang G, Zhang L, He M. Incidence of and factors associated with myopia and high myopia in Chinese children, Based on Refraction Without Cycloplegia. JAMA Ophthalmol. 2018;136(9): 1017-24.

17. Chen JC, Schmid KL, Brown B. The autonomic control of accommodation and implications for human myopia development: a review. Ophthalmic Physiol Opt. 2003;23(5):401-22.

18. Zhu H, Yu JJ, Yu RB, Ding H, Bai J, Chen J, Liu H. Association between childhood strabismus and refractive error in Chinese preschool children. PLoS One. 2015;10(3):e0120720.

19. Leone JF, Cornell E, Morgan IG, Mitchell P, Kifley A, Wang JJ, Rose KA. Prevalence of heterophoria and associations with refractive error, heterotropia and ethnicity in Australian school children. Br J Ophthalmol. 2010;94(5):542-6.

20. Momeni-Moghaddam H, Goss DA, Sobhani M. Accommodative response under monocular and binocular conditions as a function of phoria in symptomatic and asymptomatic subjects. Clin Exp Optom. 2014;97(1):36-42.

21. Ahn SJ, Yang HK, Hwang JM. Binocular visual acuity in intermittent exotropia: role of accommodative convergence. Am J Ophthalmol. 2012; 154(6):981-6 e983.

22. Walsh LA, Laroche GR, Tremblay F. The use of binocular visual acuity in the assessment of intermittent exotropia. J AAPOS. 2000;4(3):154-7. 
23. Huynh SC, Wang XY, Ip J, Robaei D, Kifley A, Rose KA, Mitchell P. Prevalence and associations of anisometropia and aniso-astigmatism in a population based sample of 6 year old children. Br J Ophthalmol. 2006;90(5):597-601.

24. Jang JU, Park IJ, Jang JY. The distribution of near point of convergence, near horizontal heterophoria, and near vergence among myopic children in South Korea. Taiwan J Ophthalmol. 2016;6(4):187-92.

25. O'Connor AR, Stephenson TJ, Johnson A, Tobin MJ, Ratib S, Fielder AR. Strabismus in children of birth weight less than $1701 \mathrm{~g}$. Arch Ophthalmol. 2002;120(6):767-73.

26. Choong YF, Chen AH, Goh PP. A comparison of autorefraction and subjective refraction with and without cycloplegia in primary school children. Am J Ophthalmol. 2006;142(1):68-74.

\section{Publisher's Note}

Springer Nature remains neutral with regard to jurisdictional claims in published maps and institutional affiliations.

Ready to submit your research? Choose BMC and benefit from:

- fast, convenient online submission

- thorough peer review by experienced researchers in your field

- rapid publication on acceptance

- support for research data, including large and complex data types

- gold Open Access which fosters wider collaboration and increased citations

- maximum visibility for your research: over $100 \mathrm{M}$ website views per year

At $B M C$, research is always in progress.

Learn more biomedcentral.com/submissions 